\title{
Enfoque Ontossemiótico da Cognição e Instrução Matemática: um estudo metanalítico das teses produzidas no Brasil
}

\author{
Adriana Breda \\ Giorgio Bolondi \\ Roger de Abreu Silva
}

\begin{abstract}
Resumo: Objetiva-se analisar como se desenvolveram as pesquisas de doutorado no âmbito do Enfoque Ontossemiótico da Cognição e Instrução Matemática (EOS) no Brasil. Por meio de categorias a priori, realizouse uma metanálise de dezesseis teses de doutorado que usaram como referente teórico-analítico as ferramentas do EOS. Observa-se que 2016 e 2017 foram os anos com o maior número de teses depositadas, que a maior parte das teses se realizaram no estado de São Paulo e que, em sua maioria, tiveram como lócus de estudo cursos de capacitação docente. Constata-se que o tema mais abordado foi a formação de professores e as ferramentas mais utilizadas foram os Critérios de Adequação Didática seguida da Configuração de Objetos e Processos. Por fim, identifica-se que algumas teses articulam o EOS com outras abordagens teóricas.
\end{abstract}

Palavras-chave: Enfoque Ontossemiótico. Metanálise. Teses de doutorado. Brasil.

\section{Onto-semiotic Approach of mathematical knowledge and instruction: a meta-analytical study of theses produced in Brazil}

Doutorado em Educação em Ciências e Matemática pela Pontifícia Universidade Católica do Rio Grande do Sul (PUCRS),

Professora da Universitat de Barcelona

(UB), Barcelona, Catalunha, Espanha.

http://orcid.org/0000-0002-7764-0511

$\checkmark$ adriana.breda@ub.edu

Giorgio Bolond

Doutorado em Matemática pela University of Nizza. Professor da Libera Università di Bolzano (UNIBZ)

Bressanone, Trentino-Alto Ádige, Itália.

http://orcid.org/0000-0003-4125-7745

$\bowtie$ giorgio.bolondi@unibz.it

Roger de Abreu Silva

Doutorando em Educação pela Universidade La Salle (UNILASALLE), campus Canoas. Bolsista taxa pelo Município de Sapucaia do Sul. Professor do município de Sapucaia do Sul (RS) Sapucaia, Rio Grande do Sul, Brasil.

http://orcid.org/0000-0002-6029-1482

$\triangle$ roger.202031385@unilasalle.edu.br

Recebido em 18/06/2021 Aceito em 19/07/2021

Publicado em 26/07/2021

deIEOS como referencia teôizo un metaanálisis de dieciseis tesis doctorales, utlizando las herramientas del EOS como referencia teórico-analítica. Como resultado, se observa que el período 2016 y 2017 fueron los años con mayor número de tesis depositadas; la mayoría de las tesis se realizaron en el estado de São Paulo y se enfocaron en cursos y formación docente. También se observa que el tema más discutido fue under the Ontosemiotic Approach of Cognition and Mathematics Instruction (OSA) in Brazil. For him, through a priori categories, a meta-analysis of sixteen doctoral theses was carried out, using the tools of the EOS as a theoreticalanalytical reference. As a result, it is observed that the period 2016 and 2017 were years with the greatest number of deposited theses; the majority of thesis took place in the state of São Paulo and focused on courses and teacher training. It is also observed that the most discussed topic was the formation of the teacher and the tools most used were the Criteria of Didactic Suitability followed by the Configuration of Objects and Processes. Finally, there is an articulation of the EOS with other theoretical approaches.

Keywords: Ontosemiotic Approach. Doctoral theses. Meta-analysis. Brazil.

\section{Enfoque Ontosemiótico sobre el Conocimiento y la Instrucción Matemáticos: un estudio de metaanálisis de las tesis desarrolladas en el Brasil}

Resumen: Este artículo tiene como objetivo analizar el desarrollo de las tesis doctorales bajo el Enfoque Ontosemiótico de la Cognición y la Instrucción Matemáticos (EOS) en Brasil. Para ello, a través de categorías a priori, se realizó un metaanálisis de dieciséis tesis doctorales, utilizando las herramientas

Abstract: This article aims to analyze the development of the doctoral theses (1)

.


la formación del profesorado y las herramientas más utilizadas fueron los Criterios de Idoneidad Didáctica seguido de la Configuración de Objetos y Procesos. Finalmente, se observa una articulación del EOS con otros enfoques teóricos.

Palabras clave: Enfoque Ontosemiótico. Tesis doctorales. Metaanálisis. Brasil.

\section{Introdução}

A Educação Matemática, por se caracterizar como uma disciplina de cunho técnicocientifico, oferece-nos uma série de abordagens teórico-metodológicas que nos ajudam a descrever e explicar como o conhecimento matemático é gerado, como os processos de ensino e aprendizagem são desenvolvidos e como estes podem ser melhorados (BREDA et al., 2021; BROUSSEAU, 1989; GODINO, 2006; GODINO, BATANERO e FONT, 2019; GODINO et al., 2021; STEINER, 1985). Uma dessas abordagens teóricas é o Enfoque Ontossemiótico da Cognição e Instrução Matemática (EOS, a partir de agora) que se caracteriza por ser um marco teórico inclusivo que, ao articular e hibridizar teorias já existentes no campo da Educação Matemática, permite abordar de maneira articulada os problemas epistemológicos, ontológicos, semióticocognitivos, educativo-instrucionais, ecológicos, de otimização da instrução e de formação de professores (GODINO, BATANERO e FONT, 2019; FONT, GODINO e GALLARDO, 2013).

Para abordar e responder a estes problemas, o EOS nos oferece uma série de ferramentas teórico-analíticas-identificação, categorização das situações-problema e descrição das sequência de práticas que se realizam durante a resolução destas situações-problema; significados e configurações ontossemióticas; desenho e análise didática (análise das trajetórias e interações didáticas); análise normativa; adequação didática; dimensões e componentes do conhecimento didático-matemático e componentes da competência de análise e intervenção didática -, as quais já foram utilizadas em diversas pesquisas focalizadas em responder os problemas relacionados aos processos de ensino e aprendizagem da matemática, tanto no âmbito de diferentes temas, como no contexto de diferentes países, entre outros, Argentina, Brasil, Chile, Colômbia, Costa Rica, Equador, Espanha, Itália, México, Peru, Panamá e Venezuela (BREDA, FONT e LIMA, 2015; KAIBER, LEMOS e PINO-FAN, 2017).

Com a finalidade de obter um panorama de como esta abordagem tem sido usada no tratamento de dados das teses realizadas no Brasil, este artigo tem como objetivo analisar como se desenvolveram as pesquisas de doutorado no âmbito da abordagem Ontossemiótica no contexto brasileiro. Para isso, nas próximas seções, apresentamos com mais detalhe, o construto teórico EOS, a metodologia utilizada para coleta e análise das teses de doutorado, os resultados obtidos e algumas considerações sobre este estudo. 


\section{Enfoque Ontossemiótico da Cognição e Instrução Matemática}

Nesta seção explicamos, com um pouco de detalhe, a abordagem EOS, em um primeiro momento descrevendo os problemas abordados por este construto teórico e as ferramentas propostas para resolver a estes problemas e em um segundo momento apresentando as articulações deste construto com outras abordagens teóricas.

\subsection{EOS: problemas, ferramentas metodológicas e níveis de análise}

As bases do EOS, recentemente explicadas em Godino, Batanero e Font (2019; 2020), estão direcionadas a responder alguns problemas gerados no campo da Educação Matemática. O primeiro deles é o problema de natureza epistemológica (como a matemática surge e se desenvolve?). No EOS, assume-se que a atividade matemática é uma atividade humana centrada na resolução de problemas, os quais se realizam em um determinado tempo-espaço, por meio de uma sequência de práticas que, muitas vezes, são consideradas processos (de atribuir significado, de conjecturar, de argumentar, etc.). A ferramenta proposta pelo EOS para responder a este problema é a ação de identificar e categorizar as situações-problema e descrever a sequência de práticas que se realizam durante a resolução destas situações-problema.

O segundo é o problema de natureza ontológica (o que é um objeto matemático e que tipo de objetos intervém na atividade matemática?). No EOS, estas práticas matemáticas são atravessadas por diferentes objetos que cumprem diferentes papéis (de representação, de regulação, de explicação e de justificação). Além disso, a configuração ontossemiótica permite a articulação da noção de práticas, de objetos e de processos e as dualidades presentes entre eles. Para isso, esta abordagem nos oferece a ferramenta denominada configuração ontossemiótica de práticas, de objetos e de processos (GODINO, 2014).

O terceiro é de natureza semiótico-cognitiva (o que significa conhecer um objeto matemático? O que é um objeto para um sujeito, em um determinado momento, circunstância e contexto dado?). Para responder a este problema, o EOS assume o princípio de que 0 conhecimento de um objeto, por parte de um sujeito (seja ele individual ou instituição), é o conjunto de funções semióticas que este sujeito pode estabelecer nas quais se põe em jogo o objeto como expressão e conteúdo. Além disso, a correspondência entre um objeto e o sistema de práticas onde tal objeto intervém é interpretado como o "significado do referido objeto" (institucional ou pessoal). Para delimitar os significados de um objeto matemático o EOS propõe a ferramenta 
denominada análise dos sistemas de práticas (pessoais e institucionais) e das configurações ontossemióticas implicadas nos mesmos (GODINO, 2014; GODINO e BATANERO, 1994).

O quarto está relacionado com o âmbito educativo- instrucional (o que é o ensino? O que é a aprendizagem? Como se relacionam? Que tipos de interação entre sujeitos, conhecimento e recursos devem ser implementados nos processos instrucionais para otimizar a aprendizagem?). Nesta abordagem, postula-se que a aprendizagem tem como propósito a apropriação dos significados e objetos institucionais pelos alunos, permitindo-os abordar a solução de certos problemas e se desenvolverem como pessoa. Além disso, o estudo dos significados pessoais dos alunos são um componente essencial do problema educacional, já que a apropriação dos significados institucionais pretendidos é condicionada pelos significados pessoais iniciais dos alunos. Para estudar os processos instrucionais, no EOS, realiza-se a análise da configuração didática (sequência de ações docentes e discentes e meios usados para abordar o estudo de uma situação problema) e a trajetória didática (sequência de configurações didáticas). A otimização dos processos de ensino e aprendizagem requer levar em consideração fatores de cunho global e em muitos casos local pois, dadas as condições fixadas in loco, é necessário questionar as circunstâncias e os recursos necessários para a otimização dos processos de ensino e aprendizagem.

O quinto é o problema de tipo ecológico (quais fatores condicionam e sustentam 0 desenvolvimento dos processos educativos e quais normas os regulam?). O EOS considera essencial identificar os fatores $\mathrm{e}$ as normas que direcionam os processos de ensino $\mathrm{e}$ aprendizagem, pois possibilita avaliar a relevância das intervenções de professores e alunos, tendo em conta: o conjunto de fatores e normas que condicionam o ensino e a aprendizagem; mudanças nos tipos de padrões que ajudam a melhorar a função e o controle dos processos instrucionais; identificação de maneiras de agir sobre alguns fatores que influenciam o sistema. A ferramenta disponibilizada pelo EOS para identificar este conjunto de normas é nomeada de tipos de normas e meta-normas (GODINO, 2014, p. 38).

O sexto problema se relaciona com a otimização dos processos de ensino e aprendizagem (que tipo de ações e recursos deveriam ser implementados em um processo de instrução realizado em um determinado contexto para que se possa otimizar a aprendizagem da matemática?). Para afrontar a este problema a abordagem EOS oferece princípios, não considerados como regras ou leis gerais, denominados critérios de adequação didática $(\mathrm{Cl})$, gerados por meio de um consenso na comunidade de Educação Matemática (BREDA, FONT e PINO-FAN, 2018) de como se deve levar a cabo os processos de ensino e aprendizagem da matemática e de como se poderiam 
melhorar ditos processos. Tais critérios devem ser aplicados localmente, nesse sentido, eles devem ser avaliados e adaptados pelo professor e devem referir-se a cada uma das facetas envolvidas nos processos de instrução matemática: epistêmica, ecológica, cognitiva, afetiva, interacional e mediacional (GODINO, 2013; BREDA, PINO-FAN e FONT, 2017).

$E$, finalmente, o sétimo problema se relaciona com a formação de professores (quais conhecimentos e competências os professores devem possuir para otimizar os processos de ensino e aprendizagem de matemática?). No EOS a formação de professores deve levar em conta e considerar as diferentes dimensões, fases, facetas e niveis de análise envolvidos nos processos de ensino e aprendizagem de matemática. Além disso, os professores devem ter o conhecimento didático-matemático necessário para analisar e compreender os processos instrucionais e as competências profissionais necessárias para uma ação adequada em tais processos. As ferramentas propostas pelo EOS para afrontar a este problema são: dimensões e componentes do conhecimento didático-matemático (PINO-FAN e GODINO, 2015) e componentes da competência de análise e intervenção didática (GODINO et al., 2017).

Em resumo, para responder a estas perguntas, o EOS propõe cinco níveis de análise sobre os processos de instrução (FONT; PLANAS; GODINO, 2010), 1) Identificação de práticas matemáticas; 2) elaboração das configurações de objetos e processos matemáticos; 3) análise das trajetórias e interações didáticas; 4) identificação do sistema de normas e meta-normas; e 5) avaliação da adequação didática do processo instrucional. 0 primeiro tipo de análise explora as práticas matemáticas realizadas em um processo de instrução matemática. O segundo enfoca os objetos e processos matemáticos envolvidos na realização das práticas, bem como aqueles que delas emergem. $O$ terceiro tipo de análise didática é orientado, sobretudo, para a descrição dos padrões de interação (LEGUIZAMÓN, 2017), configurações didáticas e sua articulação sequencial em trajetórias didáticas. 0 quarto tipo de análise está enfocado nas normas que regulam 0 processo instrucional (GODINO et al., 2009). 0 quinto tipo está baseado nas quatro análises anteriores e visa identificar potenciais melhorias para o processo instrucional em novas implementações (BREDA; FONT e PINO-FAN, 2018; GODINO, 2013; MALET; GIACOMONE e REPETTO, 2021). Além destas, existe o modelo de Conhecimentos e Competências DidáticoMatemáticos (CCDM) utilizado no âmbito da formação de professores. Em Breda et al. (2021) e Kaiber, Lemos e Pino-Fan (2017) se explicam sinteticamente os quatro primeiros níveis. Em Breda, Font e Pino-Fan (2018) explica-se com profundidade o quinto nível - Critérios de Adequação Didática $(\mathrm{Cl})-$. Os critérios, componentes e indicadores podem ser encontrados, detalhadamente, em Breda, Pino-Fan e Font (2017). 


\subsection{EOS: aplicações das ferramentas em diferentes temas}

Os temas ${ }^{1}$ relacionados ao ensino e a aprendizagem da matemática que já tiveram tratamento analítico por meio das ferramentas do EOS são: formação de professores, ensino da álgebra, ensino da geometria, ensino do cálculo, ensino da probabilidade e estatística, ensino da aritmética, ensino das ciências experimentais, ensino da demonstração e prova, ensino na Educação Infantil, Estudos de Aula, intuição, lógica, metacognição, representações e metáforas. As pesquisas relacionadas a cada tema utilizam uma ou mais de uma das ferramentas do EOS.

A modo de exemplo, por um lado, algumas pesquisas no âmbito da formação de professores utilizam as ferramentas adequação didática, dimensões e componentes do conhecimento didático-matemático (BREDA; PINO-FAN e FONT, 2017). Outras, enfocadas na formação de professores em contextos de Estudos de Aula (Lesson Study), utilizam as ferramentas: identificação de práticas matemáticas; elaboração de configurações de objetos e processos matemáticos; análise das trajetórias e interações didática; identificação do sistema de normas e meta-normas (BREDA et al., 2021) e adequação didática do processo instrucional (HUMMES et al., 2020). Para o tema ensino da geometria é possível identificar estudos que usaram, por exemplo, a ferramenta significados e configurações ontossemióticas (MOLINA; FONT e PINO-FAN, 2019), bem como trabalhos que utilizaram as noções de identificação de práticas matemáticas e tipos de problemas e elaboração de configurações epistêmicas e cognitivas de objetos e processos matemáticos (FERNÁNDEZ; GODINO; CAJARAVILLE, 2012). Por outro lado, com a finalidade de atender e responder ao princípio de que os objetos matemáticos emergem das práticas, o qual o torna um objeto complexo, é possivel identificar o uso da ferramenta denominada configurações de objetos e processos matemáticos, em particular, a configuração dos diferentes significados de um objeto matemático e suas articulações, ferramenta aplicada em muitas pesquisas enfocadas nos diferentes temas supracitados. Alguns exemplos estão citados em Font, Pino-Fan e Breda (2020, p. 116-118).

1 As publicações referentes aos temas mencionados podem ser encontradas na página web do Enfoque Ontossemiótico (EOS). Disponível em: http://enfoqueontosemiotico.ugr.es/index.html. Último acesso em: 25 de junho de 2021. 


\subsection{EOS: articulação entre diferentes abordagens teóricas}

O EOS, por caracterizar-se como uma abordagem teórico inclusiva, apresenta sua gênese e funcionamento na articulação de diferentes abordagens teóricas. Um dos trabalhos de articulação, relaciona-se com a noção de significado e sentido (GODINO; BURGOS e GEA, 2021). Nele, realiza-se uma descrição das várias abordagens dadas à noção de significado e se aterrissa à defendida pelo EOS - incorporar os pressupostos semióticos, ontológicos e epistemológicos de teorias semióticas gerais de Louis Hjelmslev, Charles Sanders Peirce e Ludwing Wittgenstein, além de analisar como os objetos matemáticos são abordados em três teorias: a lógico-realista de Friedrich Ludwig Gottlob Frege, a teoria dos campos conceituais de Gérard Vergnaud e o triângulo epistemológico de Horst Steinbring-identificando concordâncias e complementariedades entre estas e a abordagem EOS. Outro estudo realizado versa sobre às conexões matemáticas, por meio do estudo da Teoria Estendida das Conexões Matemáticas (ETC) e da abordagem Ontossemiótica (EOS) (RODRÍGUEZ-NIETO et al., 2021a; 2021b). Em particular, identificam-se as concordâncias e complementaridades nas respetivas concepções de conexões matemáticas, em resultado da aplicação destes enquadramentos teóricos ao protocolo de resposta de um aluno na resolução de uma tarefa sobre a derivada. A principal conclusão é que ambas as teorias se complementam para fazer uma análise mais detalhada das conexões matemáticas.

Também, observa-se concordâncias e complementaridades entre a teoria da objetivação (TO) de Luis Radford e o EOS (GODINO; BELTRAN-PELICER e BURGOS, 2020). Para contextualizar a reflexão, utiliza-se o relato de uma pesquisa empírica sobre a interpretação de um gráfico cartesiano que representa o movimento relativo, levantado no âmbito da teoria da objetivação. Embora ambas as teorias compartilhem princípios socioculturais sobre a natureza da matemática e dos processos de aprendizagem, os autores concluem que na análise das dimensões epistemológica, ontológica e semiótico-cognitiva, e as implicações dessas diferenças na dimensão instrucional apresentam ênfases distintas. Além dessa articulação, há a de noção de objeto matemático por meio da teoria após de Ed Dubinski e da abordagem Ontossemiótica (EOS), para comparar e contrastar como elas conceituam dita noção (FONT et al., 2015). Os resultados do estudo mostram alguns pontos em comum e algumas ligações entre essas teorias e apontam para a existência de uma complementaridade entre os seus construtos. Um estudo subsequente, com a finalidade de identificar os objetos primários presentes nas construções mentais de estudantes universitários, quando resolvem problemas sobre o gráfico de funções, mostra potencialidade do uso da APOS e EOS e a possibilidade de fazer este tipo de análise com outros objetos matemáticos (BORJl et al., 2018). 
As noções de registo de representação semiótica (TRRS) de Raymond Duval e de configuração ontossemiótica do EOS, também foram relacionadas. Godino et al. (2016) analisam uma tarefa que requer a formulação de uma conjectura e a sua demonstração recorrendo às representações icônicas e algébricas, aplicando estes dois instrumentos teóricos distintos. Concluem que nas análises realizadas com o TRRS é possível identificar contradições na atividade cognitiva do sujeito e estas são determinadas se a tarefa foi resolvida com sucesso ou não. Por outro lado, com as ferramentas do EOS é possível dar uma explicação, do ponto de vista epistêmico, sobre quais são as deficiências do conhecimento do sujeito sobre um determinado problema, identificando e descrevendo detalhadamente os objetos e processos matemáticos envolvidos nas práticas matemáticas. Um estudo similar a este foi realizado por Pino-Fan et al. (2015).

Estudaram-se, ademais, as semelhanças, diferenças e complementariedades dos modelos teóricos: Teoria de Situações Didáticas, a Teoria Antropológica do Didático e a Teoria de Campos Conceituais com a finalidade de estabelecer marco unificado para o estudo dos fenômenos cognitivos e instrucionais em didática da matemática (GODINO et al., 2006). Especificamente, os autores mostram como a ontologia matemática, proposta no EOS, junto com a noção de função semiótica podem contribuir para o progresso e articulação coerente de tais teorias. D'Amore e Godino (2007) apresentam as principais características de dois pontos de vista usados como marcos teóricos de referência em investigações realizadas em Didática da Matemática, denominados antropológico e ontossemiótico com o objetivo de enfatizar analogias e diferenças entre estas duas aproximações e abrir a porta para outros desenvolvimentos teóricos. Wilhelmi, Font e Godino (2005) confrontam a forma de produção e desenvolvimento de noções teóricas na teoria das situações didáticas e na abordagem ontológica e semiótica e, ao mesmo tempo, as formas de aplicação e funcionamento de seus métodos de pesquisa.

Drijvers et al. (2013) fizeram uma reflexão sobre a perspectiva da gênese instrumental e o EOS e analisaram, com estas lentes teóricas, um episódio de ensino e aprendizagem. Segundo os autores, os resultados desta análise conjunta fornecem uma visão rica sobre o fenômeno observado e ajudam a identificar as possibilidades e restrições de cada uma das duas abordagens e as possibilidades de articulá-las. Também, estudaram-se as características básicas da Etnomatemática e do EOS, apresentando os referenciais teóricos de cada uma delas, comparando questões paradigmáticas abordadas e identificando algumas concordâncias e complementaridades entre as duas abordagens (OLIVERAS e GODINO, 2015). 
Por fim, o EOS apresenta um modelo de conhecimentos do professor que integra e amplia os desenvolvimentos e avanços dos diversos modelos sobre o conhecimento do professor de matemática, especialmente de Lee Schulman e colaboradores e de Deborah Ball e colaboradores. Como resultado, o EOS apresenta um modelo de conhecimento didático-matemático composto por três dimensões (matemática, didática e meta didático-matemática) (GODINO et al., 2017; PINO-FAN e GODINO, 2015).

Em síntese, pode-se concluir que o EOS apresenta articulação com os diferentes marcos teóricos: noção de significado de Louis Hjelmslev, Charles Sanders Peirce e Ludwing Wittgenstein, Friedrich Ludwig Gottlob Frege, Gérard Vergnaud e Horst Steinbring; Teoria Extendida das Conexões Matemáticas; Teoria da Objetivação de Luis Radford; Teoria APOS de Ed Dubinski; Teoria dos Registros das Representações Semióticas de Raymond Duval; Teoria de Situações Didáticas de Guy Brosseau, Teoria Antropológica do Didático de Yves Chevallard e Teoria de Campos Conceituais de Gérard Vergnaud; Teoria da Genesis Instrumental; Etnomatemática; Conhecimento do Professor de Lee Schulman e Deborah Ball.

\section{Metodologia: a busca a síntese e a análise do material}

Para atingir o objetivo de analisar como se desenvolveram as pesquisas de doutorado no âmbito da abordagem Ontossemiótica no contexto brasileiro, a abordagem metodológica escolhida para essa pesquisa é do tipo qualitativa e consiste no levantamento e análise das teses desenvolvidas na abordagem EOS realizadas no Brasil. Segundo Moraes e Galiazzi (2011), a pesquisa qualitativa pretende aprofundar a compreensão dos fenômenos que investiga a partir de uma análise rigorosa e criteriosa desse tipo de informação; a intenção é a de compreender e "[...] reconstruir conhecimentos existentes sobre os temas investigados" (MORAES e GALIAZZI, 2011, p. 11). Devido a estes aspectos, e em função do objetivo proposto neste trabalho, optamos por considerar na análise todas as teses desenvolvidas no Brasil dentro da abordagem teórica EOS. Na sequência, explicamos como foi realizada a busca e identificação das teses de doutorado, como foi realizado o processo de análise e, por fim, apresenta-se uma síntese das mesmas. 


\subsection{Busca e identificação das teses}

A busca pelas teses que usaram a abordagem EOS desenvolvidas no Brasil foi realizada por meio de dois repositórios: Biblioteca Digital Brasileira de Teses e Dissertações ${ }^{2}$ e Catálogo de Teses e Dissertações da Capes ${ }^{3}$. Também, de forma complementar, foi utilizada a página web do Enfoque Ontossemiótico da Cognição e Instrução Matemática ${ }^{4}$. As palavras-chave utilizadas na busca foram: Abordagem Ontossemiótica, Enfoque Ontosemiótico, EOS, Onto-semiotic Approach, Critérios de Idoneidade Didática, Critérios de Adequação Didática, Critérios de Idoneidade, Idoneidade Didática, Adequação Didática, Modelo de Conhecimentos e competências DidáticoMatemáticos (CCDM), Modelo de Conhecimentos Didático- Matemáticos (CDM) e Godino. A busca foi realizada por cada palavra-chave separadamente e, também, através da combinação entre elas, por exemplo, a combinação "Modelo de Conhecimentos Didático- Matemáticos (CDM) e EOS".

\subsection{Metodologia de análise}

A análise das teses foi realizada por meio da metodologia metanálise qualitativa que, segundo Rodrigues (2002) consiste em compreender, através de categorias pré-determinadas, algumas semelhanças e diferenças dos materiais publicados dentro de uma mesma área de pesquisa. Nesse caso, denota-se a análise das produções realizadas no âmbito da teoria Enfoque Ontossemiótico da Cognição e Instrução Matemática (EOS) desenvolvidas no Brasil.

É importante salientar que as categorias a priori têm a função de orientar o processo interpretativo, visando um aprimoramento da área analisada (PINTO, 2013). Nesse sentido, foram definidas seis categorias que consideramos importantes e necessárias para obtermos uma avaliação mais aprofundada do tema. São elas: I) Número de teses produzidas por ano; II) Número de teses desenvolvidas por estados brasileiros; III) Níveis de ensino; IV) Temas abordados; V) Ferramentas do EOS utilizadas; VI) Articulação do EOS com outras abordagens teóricas. As três primeiras categorias (I, II e III) foram definidas no intuito de obter um panorama quantitativo das teses produzidas, respectivamente, por ano, por estados brasileiros e por níveis de ensino. As três últimas categorias (IV, V e VI) foram estabelecidas com base nas pesquisas e estudos realizados no âmbito do Enfoque Ontossemiótico, cujas publicações presentes na página web do EOS, entre outros aspectos, estão organizadas em: temas abordados, ferramentas utilizadas e articulação do

2 https://bdtd.ibict.br/vufind/

3 https://catalogodeteses.capes.gov.br/catalogo-teses/\#!/

$4 \mathrm{http}: / /$ enfoqueontosemiotico.ugr.es/pages/tesisdoctorales.html

Revemop, Ouro Preto, Brasil, v. 3, e202117, p. 1-28, 2021 
EOS com outras abordagens teóricas. Uma análise similar à que se apresenta neste artigo pode ser encontrada em Breda et al. (2016).

\subsection{Síntese das teses identificadas}

Ao realizar a busca, identificamos dezesseis teses de doutorado desenvolvidas em universidades brasileiras. A seguir apresentamos um quadro-síntese (Tabela 1) abordando de forma sistemática as dezesseis teses, contemplando, respectivamente, o codinome da tese (T1, T2, T3, etc.), o título, autor e ano, instituição e estado e, por fim, a síntese de cada uma delas. 
Tabela 1: Lista das teses identificadas.

\begin{tabular}{|c|c|c|c|c|}
\hline Tese & Título & $\begin{array}{c}\text { Autor/An } \\
0\end{array}$ & $\begin{array}{c}\text { Instituição/ } \\
\text { Estado }\end{array}$ & Síntese da tese \\
\hline $\mathrm{T} 1$ & $\begin{array}{l}\text { Ensino e aprendizagem do } \\
\text { modelo Poisson: uma } \\
\text { experiência com modelagem }\end{array}$ & $\begin{array}{l}\text { Maria } \\
\text { Inez } \\
\text { Rodrigue } \\
\text { s Miguel } \\
\text { (2005) }\end{array}$ & $\begin{array}{l}\text { Pontifícia } \\
\text { Universidade } \\
\text { Católica de } \\
\text { São Paulo/ } \\
\text { São Paulo }\end{array}$ & $\begin{array}{l}\text { A pesquisa centra-se no processo de ensino e aprendizagem do Modelo de Poisson de alunos de } \\
\text { graduação em Engenharia Elétrica e Ciência da Computação de uma Instituição de Ensino Superior. } \\
\text { Ao aplicar uma sequência de ensino, elaborada com base nas etapas de Modelagem Matemática e } \\
\text { usar as ferramentas da Engenharia Didática, da praxeologia de Yves Chevallard e da determinação } \\
\text { de elementos de significado do EOS, conclui-se que todas as etapas de modelagem puderam ser } \\
\text { interpretadas, adaptadas e consideradas essenciais. Embora tenham sido identificadas algumas } \\
\text { dificuldades por parte dos alunos, muitos significados de referência foram adquiridos, além de } \\
\text { constatar que os registros de representação simbólica persistiram durante todo o processo de estudo. }\end{array}$ \\
\hline $\mathrm{T} 2$ & $\begin{array}{l}\text { A produção de significados } \\
\text { matemáticos em um contexto } \\
\text { de aulas exploratório- } \\
\text { investigativas }\end{array}$ & $\begin{array}{l}\text { Adriana } \\
\text { Assis } \\
(2012)\end{array}$ & $\begin{array}{l}\text { Universidade } \\
\text { Federal de } \\
\text { Minas } \\
\text { Gerais/ } \\
\text { Minas } \\
\text { Gerais }\end{array}$ & $\begin{array}{l}\text { Estudou-se como se dá o processo de produção de significados pelos alunos do sétimo ano do } \\
\text { Ensino Fundamental, quando trabalham com atividades exploratório-investigativas. Partindo de uma } \\
\text { perspectiva semiótico-cultural para a produção de significados de Luis Radford e dos cinco níveis de } \\
\text { análise propostos pelo EOS, os resultados indicam que as atividades exploratório-investigativas em } \\
\text { sala de aula são fortemente condicionadas pela afetividade (normas e metanormas, atitudes, } \\
\text { emoções, motivação, etc.); materialidade (disponibilidade de tempo, meios, etc.); interação; tarefa } \\
\text { proposta (representatividade matemática, possibilidade de emergência ZDP, adaptação ao currículo, } \\
\text { sociedade, etc.); familiaridade dos alunos (e do professor) com esse tipo de atividade, etc. }\end{array}$ \\
\hline T3 & $\begin{array}{l}\text { Práticas matemáticas no } \\
\text { plano cartesiano: um estudo } \\
\text { da coordenação de registros } \\
\text { de representação }\end{array}$ & $\begin{array}{l}\text { Afrânio } \\
\text { Austrege } \\
\text { silo Thiel } \\
\text { (2013) }\end{array}$ & $\begin{array}{l}\text { Universidade } \\
\text { Federal de } \\
\text { Santa } \\
\text { Catarina/ } \\
\text { Santa } \\
\text { Catarina }\end{array}$ & $\begin{array}{l}\text { Com o objetivo delinear procedimentos norteadores para compreensão e análise das representações } \\
\text { no plano cartesiano no Ensino Fundamental. Através do estudo dos significados institucionais e } \\
\text { pessoais, a partir da Teoria dos Registros de Representação Semiótica de Raymond Duval (TRRS) } \\
\text { e do EOS, pôde-se detectar avanços significativos na aprendizagem dos alunos quanto às práticas } \\
\text { matemáticas no plano cartesiano. }\end{array}$ \\
\hline T4 & $\begin{array}{l}\text { Avaliação das } \text { atitudes no } \\
\text { curso de Estatística: } \\
\text { contextos universitários } \\
\text { latino-americanos }\end{array}$ & $\begin{array}{l}\text { Ana } \\
\text { Sofía } \\
\text { Aparício } \\
\text { Pereda } \\
\text { (2014) }\end{array}$ & $\begin{array}{l}\text { Universidade } \\
\text { de São } \\
\text { Paulo/ } \\
\text { São Paulo }\end{array}$ & $\begin{array}{l}\text { Por meio das ferramentas denominadas sistema de práticas, significado institucional, significado } \\
\text { pessoal e objeto de estudo do EOS, realiza-se uma proposta metodológica de avaliação dos } \\
\text { processos de ensino e aprendizagem de um curso de Estatística de uma instituição de ensino } \\
\text { superior com a finalidade de analisar as atitudes dos estudantes de quatro diferentes países em } \\
\text { relação a estatística, além de realizar uma aproximação na avaliação institucional dos cursos de } \\
\text { graduação e pós-graduação dos países contemplados no estudo. }\end{array}$ \\
\hline
\end{tabular}




\begin{tabular}{|c|c|c|c|c|}
\hline Tese & Título & $\begin{array}{c}\text { Autor/An } \\
0\end{array}$ & $\begin{array}{l}\text { Instituição/ } \\
\text { Estado }\end{array}$ & Síntese da tese \\
\hline T5 & $\begin{array}{l}\text { Currículos de matemática no } \\
\text { ensino médio: um olhar sob a } \\
\text { perspectiva do Enfoque } \\
\text { Ontossemiótico do } \\
\text { conhecimento e a instrução } \\
\text { matemática }\end{array}$ & $\begin{array}{l}\text { Luísa } \\
\text { Silva } \\
\text { Andrade } \\
\text { (2014) }\end{array}$ & $\begin{array}{l}\text { Universidade } \\
\text { Luterana do } \\
\text { Brasil/ } \\
\text { Rio Grande } \\
\text { do Sul }\end{array}$ & $\begin{array}{l}\text { O presente trabalho busca investigar o desenvolvimento da Matemática no Ensino Médio (EM) de } \\
\text { escolas públicas estaduais do Rio Grande do Sul. Ao usar a noção de adequação didática (CI) e suas } \\
\text { seis dimensões (epistêmica, cognitiva, ecológica, emocional, interacional e mediacional) do EOS, } \\
\text { conclui-se que, tanto os parâmetros curriculares e orientações curriculares do EM, quanto os Planos } \\
\text { de Estudo e o discurso dos professores e supervisores apresentam elementos normativos referentes } \\
\text { ao tratamento sugerido aos conhecimentos matemáticos com relação à presença de situações } \\
\text { problema, ao uso de regras e de diferentes tipos de representações, elementos evidenciados no } \\
\text { âmbito do EOS. }\end{array}$ \\
\hline T6 & $\begin{array}{l}\text { Melhorias no ensino de } \\
\text { matemática na concepção de } \\
\text { professores que realizam o } \\
\text { mestrado Profmat no Rio } \\
\text { Grande do Sul: uma análise } \\
\text { dos trabalhos de conclusão } \\
\text { de curso }\end{array}$ & $\begin{array}{l}\text { Adriana } \\
\text { Breda } \\
(2016)\end{array}$ & $\begin{array}{l}\text { Pontifícia } \\
\text { Universidade } \\
\text { Católica do } \\
\text { Rio Grande } \\
\text { do Sul/ } \\
\text { Rio Grande } \\
\text { do Sul }\end{array}$ & $\begin{array}{l}\text { Estuda as características da análise em didática, realizada por } 25 \text { professores em seus trabalhos } \\
\text { finais de mestrado para justificar que suas propostas melhoram o ensino e a aprendizagem da } \\
\text { matemática. Através da análise com uso dos critérios de adequação didática (Cl), conclui-se que os } \\
\text { professores baseiam as suas justificativas no uso implícito dos } \mathrm{Cl} \text {, em particular epistêmico, ecológico } \\
\text { e mediacional. }\end{array}$ \\
\hline $\mathrm{T7}$ & $\begin{array}{l}\text { Conhecimentos didático- } \\
\text { matemáticos mobilizados por } \\
\text { professores dos anos iniciais: } \\
\text { uma análise sob a } \\
\text { perspectiva do Enfoque } \\
\text { Ontossemiótico }\end{array}$ & $\begin{array}{l}\text { Maria } \\
\text { Elaine } \\
\text { dos } \\
\text { Santos } \\
\text { Soares } \\
(2016)\end{array}$ & $\begin{array}{l}\text { Universidade } \\
\text { Luterana do } \\
\text { Brasil/ } \\
\text { Rio Grande } \\
\text { do Sul }\end{array}$ & $\begin{array}{l}\text { O objetivo do estudo foi investigar os conhecimentos didático-matemáticos mobilizados por um grupo } \\
\text { de professores que ensinam matemática, nos anos iniciais do Ensino Fundamental. Ao utilizar os } \\
\text { critérios de adequação didática do EOS, as análises apontam para baixa idoneidade epistêmico- } \\
\text { cognitiva, dadas as dificuldades relacionadas ao conhecimento específico do conteúdo de fraçães e } \\
\text { números decimais; média idoneidade mediacional, pois, embora utilizem recursos manipulativos na } \\
\text { prática docente, apresentam dificuldades na utilização de tecnologias digitais: media idoneidade } \\
\text { interacional, devido à apresentação do conteúdo de frações não contemplar diferentes formas de } \\
\text { representação. Por fim, foi possível identificar que a experiência do professor contribui, } \\
\text { positivamente, para o conhecimento didático-matemático. }\end{array}$ \\
\hline T8 & $\begin{array}{l}\text { Um estudo da inserção de } \\
\text { estudantes da licenciatura } \\
\text { em matemática no contexto } \\
\text { da escola pública: } \\
\text { contribuições do PIBID }\end{array}$ & $\begin{array}{l}\text { Marcos } \\
\text { Pavani } \\
\text { de } \\
\text { Carvalho } \\
(2016)\end{array}$ & $\begin{array}{l}\text { Universidade } \\
\text { Anhanguera } \\
\text { de São } \\
\text { Paulo/ } \\
\text { São Paulo }\end{array}$ & $\begin{array}{l}\text { O propósito deste estudo foi investigar contribuições do Programa Institucional de Bolsas de Iniciação } \\
\text { à Docência (Pibid). Ao usar o referente de Ball e colaboradores para analisar os conhecimentos de } \\
\text { professores e os critérios de idoneidade didática do EOS para analisar a atuação dos futuros } \\
\text { professores, conclui-se que eles, majoritariamente, utilizaram o livro didático como fonte de consulta } \\
\text { para a preparação das aulas e que a metodologia predominante adotada foi a resolução de listas de } \\
\text { exercícios. }\end{array}$ \\
\hline
\end{tabular}




\begin{tabular}{|c|c|c|c|c|}
\hline Tese & Título & $\begin{array}{c}\text { Autor/An } \\
0\end{array}$ & $\begin{array}{l}\text { Instituição/ } \\
\text { Estado }\end{array}$ & Síntese da tese \\
\hline T9 & $\begin{array}{l}\text { Modelagem Matemática e } \\
\text { mobilização de } \\
\text { conhecimentos didático- } \\
\text { matemáticos na formação } \\
\text { continuada de professores } \\
\text { dos anos iniciais }\end{array}$ & $\begin{array}{c}\text { Rogerio } \\
\text { Marques } \\
\text { Ribeiro } \\
(2016)\end{array}$ & $\begin{array}{l}\text { Universidade } \\
\text { Federal de } \\
\text { São Carlos/ } \\
\text { São Paulo }\end{array}$ & $\begin{array}{l}\text { A tese buscou investigar a formação continuada de professores de matemática dos anos iniciais do } \\
\text { Ensino Fundamental na perspectiva da Modelagem Matemática. Ao utilizar as categorias para análise } \\
\text { propostas pelo CDM do EOS e pelo Modelo do Conhecimento, proposto por Ball, conclui-se que } \\
\text { alguns elementos que constituem os conhecimentos matemáticos do professor emergiram e foram } \\
\text { articulados com as categorias do Conhecimento Comum do Conteúdo e do Conhecimento Ampliado } \\
\text { do Conteúdo, assim como com as categorias Epistêmica, de Interação, de Meios e Ecológica, } \\
\text { pertencentes à dimensão didática do CDM. }\end{array}$ \\
\hline T10 & $\begin{array}{l}\text { E Ensino de Matemática } \\
\text { proposto na coleção de livros } \\
\text { didáticos usados nos cursos } \\
\text { técnicos de nível médio do } \\
\text { IFECT Fluminense: } \\
\text { contextos e aplicações }\end{array}$ & $\begin{array}{l}\text { Vanice } \\
\text { da Silva } \\
\text { Freitas } \\
\text { Vieira } \\
(2016)\end{array}$ & $\begin{array}{l}\text { Universidade } \\
\text { Cruzeiro do } \\
\text { Sul/ } \\
\text { São Paulo }\end{array}$ & $\begin{array}{l}\text { O estudo teve como objetivo analisar os seis tipos de objetos primários propostos pelo EOS em uma } \\
\text { coleção de livros didáticos de Matemática utilizada nos Cursos Técnicos integrado ao Ensino Médio. } \\
\text { Ao analisar as situações matemáticas, as linguagens, os conceitos, proposições, procedimentos e } \\
\text { argumentações, foram contabilizados os diferentes tipos de situações-problema. Além disso, } \\
\text { constatou-se que os objetos primários, linguagem, conceitos, proposições, procedimentos e } \\
\text { argumentações estão adequados para o nível do Ensino Médio. Verificou-se, também, que a coleção } \\
\text { apresenta expressividade no número de atividades de cálculos algorítmicos, em relação às de } \\
\text { estabelecimento de riqueza de processos. }\end{array}$ \\
\hline T11 & $\begin{array}{l}\text { Um estudo do programa de } \\
\text { consolidação das } \\
\text { licenciaturas no contexto da } \\
\text { formação inicial de } \\
\text { professores de matemática }\end{array}$ & $\begin{array}{l}\text { José } \\
\text { Fernande } \\
\text { s da } \\
\text { Silva } \\
(2017)\end{array}$ & $\begin{array}{l}\text { Universidade } \\
\text { Anhanguera } \\
\text { de São } \\
\text { Paulo/ } \\
\text { São Paulo }\end{array}$ & $\begin{array}{l}\text { No intuito de investigar as contribuições do Prodocência no processo de construção de } \\
\text { conhecimentos, competências e desenvolvimento profissional de futuros professores de Matemática } \\
\text { e professores formadores, utilizou-se a CCDM do EOS. Conclui-se que, tanto futuros professores } \\
\text { quanto professores formadores demonstram o desenvolvimento do conhecimento pedagógico do } \\
\text { conteúdo, em especial, nos aspectos relacionados à faceta mediacional. No que concerne ao } \\
\text { conhecimento do conteúdo específico (faceta epistêmica), percebe-se aspectos do conhecimento } \\
\text { comum do conteúdo, do conhecimento especializado e do conhecimento ampliado do conteúdo. }\end{array}$ \\
\hline T12 & $\begin{array}{l}\text { Um estudo sobre os } \\
\text { conhecimentos didáticos- } \\
\text { matemáticos de } \\
\text { probabilidader com } \\
\text { professores de matemática } \\
\text { dos anos finais do ensino } \\
\text { fundamental }\end{array}$ & $\begin{array}{l}\text { José } \\
\text { Ivanildo } \\
\text { Felisbert } \\
\text { o de } \\
\text { Carvalho } \\
\text { (2017) }\end{array}$ & $\begin{array}{l}\text { Universidade } \\
\text { Anhanguera } \\
\text { de São } \\
\text { Paulo/ } \\
\text { São Paulo }\end{array}$ & $\begin{array}{l}\text { O estudo tratou de analisar como um programa formativo favorece a construção dos conhecimentos } \\
\text { didáticos-matemáticos sobre probabilidade em professores de matemática em exercício. Por meio } \\
\text { do modelo do Conhecimento Didático-Matemático, a teoria da Idoneidade Didática do EOS e a } \\
\text { Engenharia Didática, identificou-se a falta de conhecimentos iniciais dos participantes sobre } \\
\text { probabilidade. Constatou-se também, que os professores desenvolveram e ampliaram } \\
\text { conhecimentos concernentes à probabilidade e ao seu ensino, os ressignificando. Identifica-se que } \\
\text { o Cl do curso foi considerado alto. }\end{array}$ \\
\hline
\end{tabular}




\begin{tabular}{|c|c|c|c|c|}
\hline Tese & Título & $\begin{array}{c}\text { Autor/An } \\
0\end{array}$ & $\begin{array}{l}\text { Instituição/ } \\
\text { Estado }\end{array}$ & Síntese da tese \\
\hline T13 & $\begin{array}{l}\text { A abordagem dada à taxa de } \\
\text { variação no livro didático do } \\
\text { ensino médio e a sua relação } \\
\text { com o conceito da derivada } \\
\text { no livro didático do ensino } \\
\text { superior }\end{array}$ & $\begin{array}{l}\text { Rogerio } \\
\text { dos } \\
\text { Santos } \\
\text { Lobo } \\
(2017)\end{array}$ & $\begin{array}{l}\text { Pontifícia } \\
\text { Universidade } \\
\text { Católica de } \\
\text { São Paulo/ } \\
\text { São Paulo }\end{array}$ & $\begin{array}{l}\text { A pesquisa buscou investigar os significados de variação, de taxa de variação e da derivada em livros } \\
\text { didáticos do ensino médio (EM) e superior (ES). Ao utilizar a noção de registro das representações } \\
\text { semióticas de Raymond Duval e o a noção epistêmica da representatividade dos objetos } \\
\text { matemáticos do EOS. Conclui-se que, quanto aos significados de variação e taxa de variação, os } \\
\text { livros do EM contemplam apenas um dos significados parciais. No caso da derivada, nos livros do } \\
\text { ES, o significado abordado é o derivada como limite, portanto, pouco representativo para a } \\
\text { construção global do conceito. }\end{array}$ \\
\hline T14 & $\begin{array}{l}\text { Estudos de recuperação no } \\
\text { ensino fundamental: uma } \\
\text { investigação no âmbito da } \\
\text { geometria sob a perspectiva } \\
\text { do Enfoque Ontossemiótico } \\
\text { do conhecimento e da } \\
\text { instrução matemática }\end{array}$ & $\begin{array}{l}\text { Andrielly } \\
\text { Viana } \\
\text { Lemos } \\
(2017)\end{array}$ & $\begin{array}{l}\text { Universidade } \\
\text { Luterana do } \\
\text { Brasil/ } \\
\text { Rio Grande } \\
\text { do Sul }\end{array}$ & $\begin{array}{l}\text { Apresenta-se a análise da implementação de uma proposta de estudos de recuperação de } \\
\text { Geometria, enfocada no uso das tecnologias digitais, aplicada no nono ano do Ensino Fundamental. } \\
\text { Por meio do uso dos } \mathrm{Cl} \text {, conclui-se que as dimensões epistêmica e cognitiva apresentam fragilidades } \\
\text { nos argumentos e síntese, tanto no material produzido, como nos significados estabelecidos pelos } \\
\text { estudantes. Já, as demais dimensões atingiram altas adequações. }\end{array}$ \\
\hline T15 & $\begin{array}{l}\text { Relação professor-materiais } \\
\text { curriculares em Educação } \\
\text { Matemática: uma análise a } \\
\text { partir de elementos dos } \\
\text { recursos do currículo e dos } \\
\text { recursos dos professores }\end{array}$ & $\begin{array}{l}\text { Kátia } \\
\text { Cristina } \\
\text { Lima } \\
\text { Santana } \\
(2017)\end{array}$ & $\begin{array}{l}\text { Pontifícia } \\
\text { Universidade } \\
\text { Católica de } \\
\text { São Paulo/ } \\
\text { São Paulo }\end{array}$ & $\begin{array}{l}\text { A pesquisa buscou analisar como professores em exercício avaliavam o material curricular por eles } \\
\text { utilizados para planejar e desenvolver as suas aulas. A partir dos estudos relacionados a análise de } \\
\text { materiais curriculares e sua relação com o professor e do modelo de Conhecimentos Didático- } \\
\text { Matemáticos (CDM) do professor do EOS, conclui-se que os conhecimentos mobilizados pelos } \\
\text { professores se referem às dimensões matemática e didática do CDM, principalmente relacionados } \\
\text { aos critérios epistêmico e cognitivo, sobressaindo-se o epistêmico. }\end{array}$ \\
\hline T16 & $\begin{array}{l}\text { Conhecimentos didático- } \\
\text { matemáticos do professor de } \\
\text { matemática para o ensino de } \\
\text { números racionais }\end{array}$ & $\begin{array}{l}\text { Patrícia } \\
\text { Pujol } \\
\text { Goulart } \\
\text { Carpes } \\
(2019)\end{array}$ & $\begin{array}{l}\text { Universidade } \\
\text { Franciscanal } \\
\text { Rio Grande } \\
\text { do Sul }\end{array}$ & $\begin{array}{l}\text { Estudou-se o desenvolvimento dos conhecimentos didático-matemáticos (CDM) sobre números } \\
\text { racionais em um grupo de professores de Matemática de Itaqui (RS). Os resultados da análise do } \\
\text { conhecimento didático, por meio da ferramenta Critérios de Adequação Didática, apontam que os } \\
\text { professores possuem pouca destreza em conectar os diferentes significados dos números racionais } \\
\text { e suas representações, além de um desconhecimento em trabalhar o processo de Resolução de } \\
\text { Problemas. }\end{array}$ \\
\hline
\end{tabular}

Fonte: Autores (2021). 


\section{Resultados}

Com o objetivo de analisar como se desenvolveram as pesquisas de doutorado no âmbito do Enfoque Ontossemiótico no contexto brasileiro, foi feito um levantamento do número de teses produzidas por ano, número de teses desenvolvidas por estados brasileiros e níveis de ensino contemplados. Também foi realizado um estudo relacionado aos temas abordados, às ferramentas do EOS utilizadas e a identificação das teses que realizaram uma articulação do EOS com outras abordagens teóricas.

Com relação as categorias número de teses por ano (Figura 1) e número de teses desenvolvidas nos diferentes estados brasileiros (Figura 2), temos o seguinte panorama:

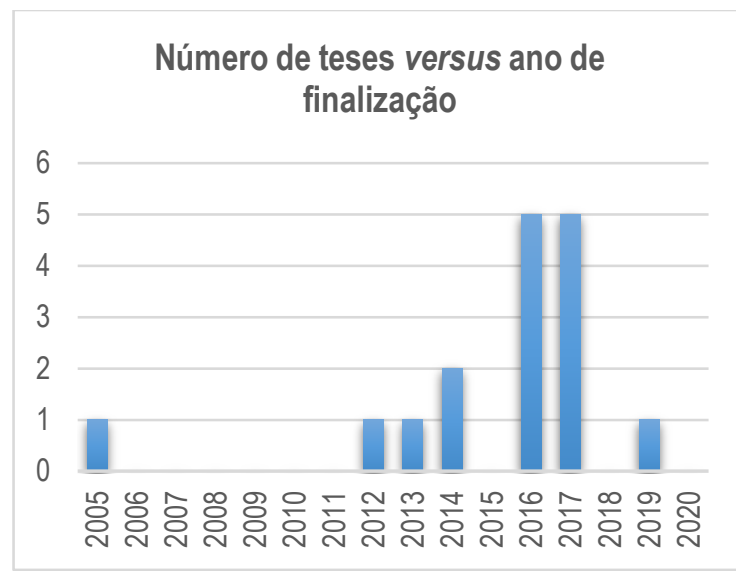

Figura 1: Número de teses por ano (Autores, 2021).

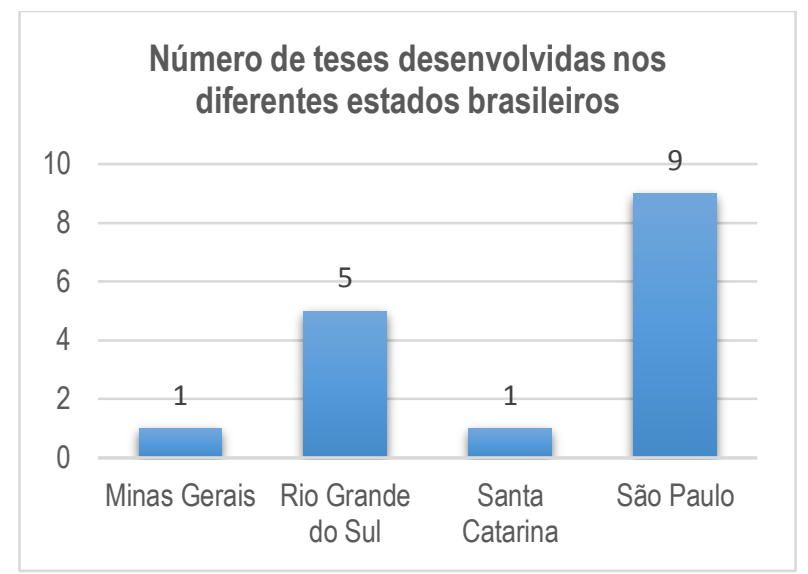

Figura 2: Número de teses por estado brasileiro.

Podemos observar que o período das teses depositadas nos repositórios de teses e dissertações mencionados na seção 3.1 vai de 2005 a 2019 e a maioria das teses desenvolvidas usando a abordagem EOS em contextos brasileiros foram finalizadas nos anos de 2016 e 2017. Por outro lado, observamos que as teses identificadas foram realizadas em universidades localizadas nos estados de Minas Gerais, Rio Grande do Sul, Santa Catarina e São Paulo, não sendo identificadas teses de doutorado, dentro desta abordagem teórica, em outros estados brasileiros. Além disso, a maioria das teses foi desenvolvida no estado de São Paulo (9 teses), seguido do estado do Rio Grande do Sul (5 teses).

Com relação à categoria níveis de ensino, foram identificados os seguintes: Ensino Fundamental, Ensino Médio, Ensino superior (graduação), Ensino Superior (pós-graduação), e cursos de capacitação para professores em exercício, não sendo identificada nenhuma pesquisa 
que tivesse como foco a Educação Infantil. Observa-se que a maioria das teses tiveram como lócus de estudo cursos para professores em exercício (T7, T9, T12, T15 e T16) e nível superior (graduação) (T1, T4, T8, T11 e T13), seguido de pesquisas aplicadas no contexto do Ensino Médio (T5, T10 e T13). Por último, pesquisas aplicadas no contexto do Ensino Superior (pós-graduação) (T4 e T6) e Ensino Fundamental (T3 e T14), conforme apresenta a Figura 3.

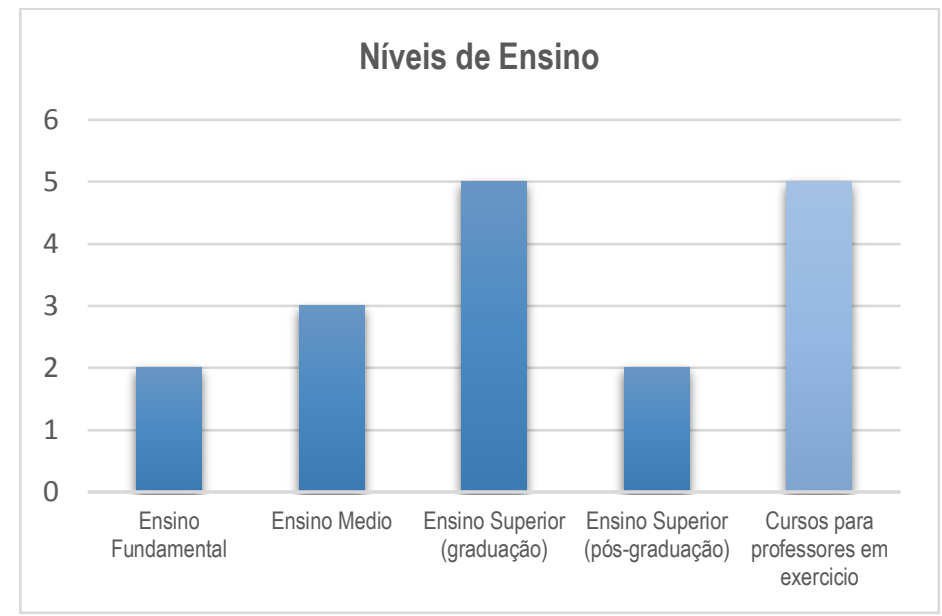

Figura 3: Níveis de ensino (Autores, 2021).

Com relação aos temas abordados-Formação de professores, Ensino da Geometria, Ensino da Aritmética e Álgebra, Ensino do Cálculo, Ensino da Probabilidade e Estatística e diversos temas-encontramos que a maioria das teses focaram seus temas na formação de professores (T6, T7, T8, T9, T11, T12, T15, T16), seguido do ensino da geometria (T3, T14) aritmética e álgebra (T16, T17), probabilidade e estatística (T4, T12) e cálculo (T13). Também, encontraram-se teses enfocadas na abordagem de outros temas: atividades exploratórioinvestigativas (T2), modelagem (T1, T9), livros textos (T10), currículo (T5). É importante salientar que algumas teses abordam mais de um tema. Por exemplo, a T16 teve como foco realizar um processo formativo com professores em exercício (tema formação de professores) sobre o objeto matemático números racionais (ensino da aritmética e álgebra). A tese T9 buscou investigar a formação continuada de professores de matemática dos anos iniciais do Ensino Fundamental (formação de professores) na perspectiva da Modelagem Matemática (tema modelagem). Já, a T12 tratou de analisar como um programa formativo favorece a construção dos conhecimentos didáticos-matemáticos sobre probabilidade (tema ensino da probabilidade e estatística) em professores de matemática em exercício (tema formação de professores).

Com relação às ferramentas do EOS utilizadas nas teses, observa-se a predominância da ferramenta Critérios de Adequação Didática (CI) (T2, T5, T6, T7, T8, T9, T11, T12, T14, T15, T16), seguido das Configurações de objetos e processos (T1, T2, T3, T4, T10, T13, T16) e modelo 
$\operatorname{CCDM}(T 7, T 9, T 11, T 12, T 15, T 16)$. A ferramenta denominada Identificação das práticas matemáticas foi utilizada nas teses (T2, $T 3, T 4, T 10)$, a Identificação de sistemas de normas e meta-normas nas teses (T2, T5) e Análise das trajetórias e interações didáticas na (T2).

É importante salientar que uma tese pode ter utilizado mais de uma ferramenta do Enfoque Ontossemiótico. Por exemplo, para estudar como se dava o processo de produção de significados pelos alunos do sétimo ano do Ensino Fundamental, quando trabalham com atividades exploratório-investigativas a T2 utilizou cinco ferramentas de análise do EOS: Critérios de Adequação Didática, Configurações de objetos e processos, Identificação das práticas matemáticas, Identificação de sistemas de normas e meta-normas e Análise das trajetórias e interações didáticas, sendo a única tese que realizou um estudo das trajetórias e interações didáticas. Por outro lado, para estudar as características da análise em didática, realizada por 25 professores em seus trabalhos finais de mestrado para justificar que suas propostas melhoram 0 ensino e a aprendizagem da matemática a T6 utilizou apenas a ferramenta Critérios de Adequação Didática (BREDA, 2020). Também se observa que muitas teses que utilizaram o modelo de conhecimentos e competências do professor (CCDM), também contemplaram como ferramenta de análise os Critérios de Adequação Didática (T7, T9, T11, T12, T15, T16). Além disso, identificase que todas as quatro teses que utilizaram a noção de Identificação das práticas matemáticas também operaram com a ferramenta Configuração de objetos e processos.

Além da identificação dos temas abordados e das ferramentas utilizadas, foi possível fazer uma relação entre estas duas categorias. $\mathrm{Na} \mathrm{T} 1$, para analisar o processo de ensino e aprendizagem do Modelo de Poisson (tema modelagem) de alunos de graduação utilizou a ferramenta Configuração de Objetos e processos. Já, a T7 para investigar os conhecimentos didático-matemáticos mobilizados por um grupo de professores (tema formação de professores) ao ensinar frações e números decimais (tema ensino da aritmética e álgebra), utilizou o modelo de conhecimentos e competências didático-matemáticas (CCDM) e os Critérios de Adequação Didática $(\mathrm{Cl})$, neste caso, esta tese aborda dois temas presentes no EOS e duas ferramentas de análise.

A T16 para estudar o desenvolvimento dos conhecimentos didático-matemáticos (CDM) sobre números racionais (tema ensino da aritmética e álgebra) em um grupo de professores de Matemática utilizou as ferramentas: Critérios de Adequação Didática e Configuração de objetos e processos (CARPES e BISOGNIN, 2021). A T3, para compreender a análise das representações no plano cartesiano (tema ensino da geometria) no Ensino Fundamental utilizou as ferramentas Identificação das práticas matemáticas e a Configuração dos objetos e processos. 
Um panorama geral da relação entre as categorias temas abordados e ferramentas utilizadas pode ser observado na Tabela 2.

Tabela 2: Temas abordados versus ferramentas do EOS utilizadas.

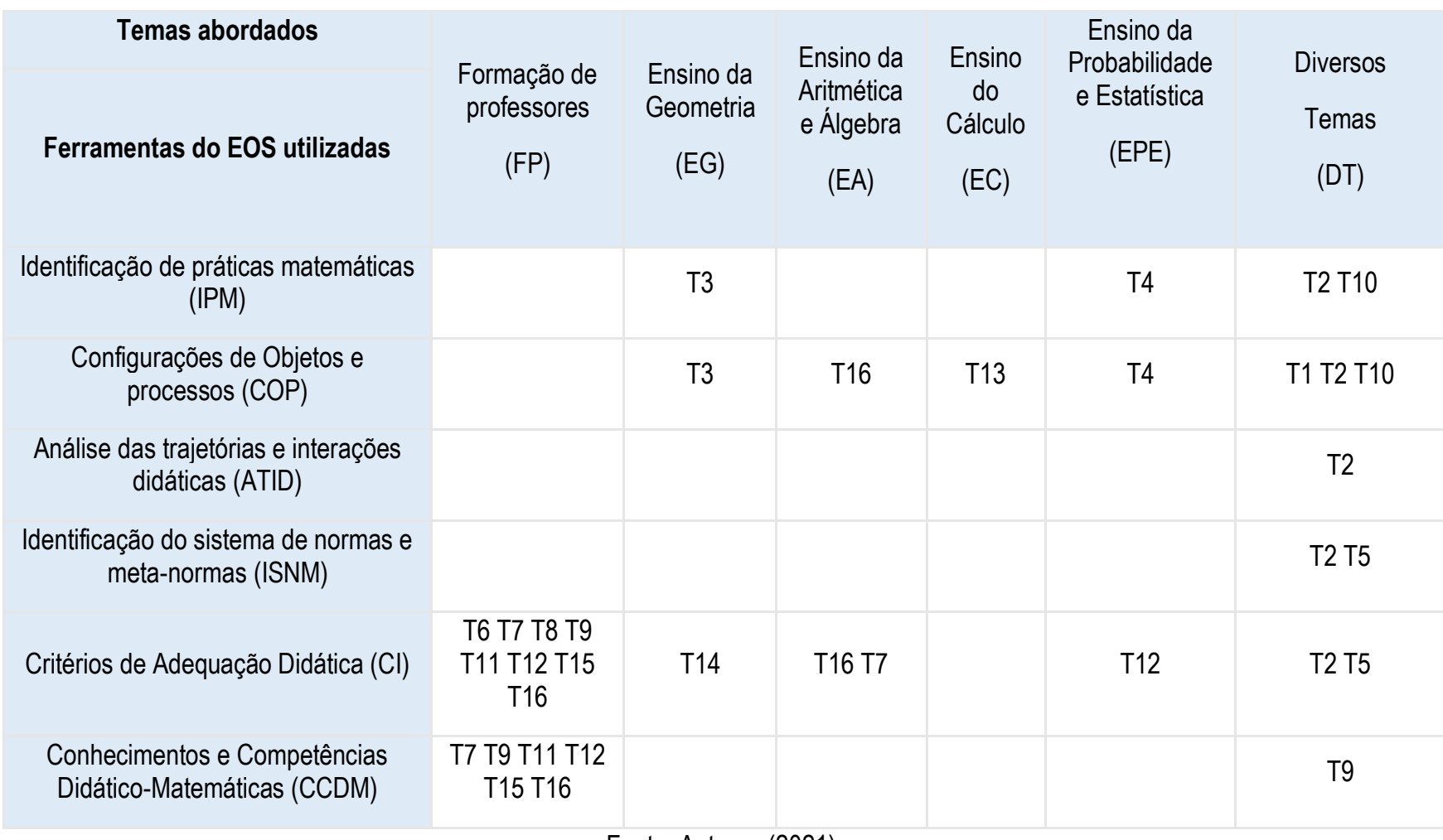

Fonte: Autores (2021).

Ao observar a tabela com mais detalhe, percebemos que pode ser estabelecida uma rede de conexões que relaciona as teses desenvolvidas com os temas abordados e as ferramentas do EOS utilizadas, conforme a Figura 4. 


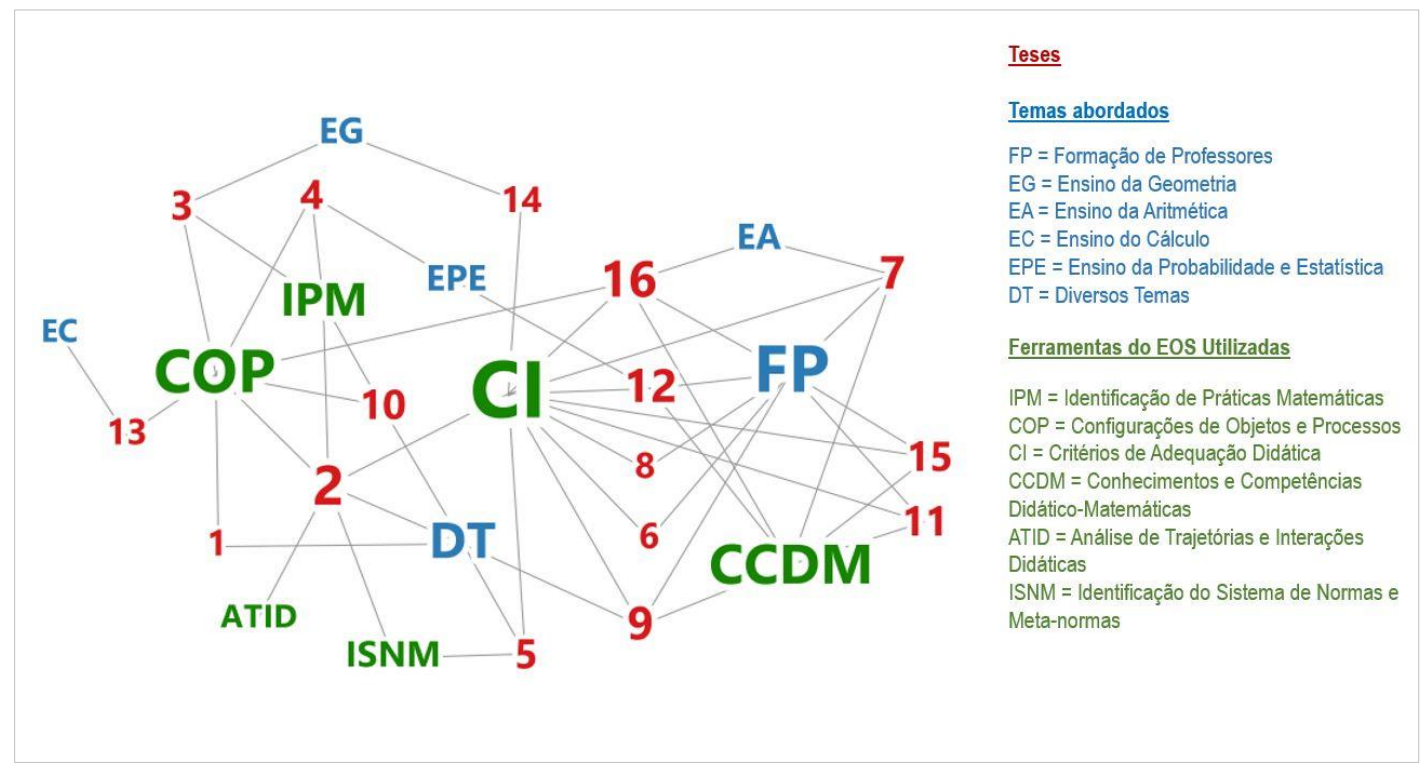

Figura 4: Rede de conexões entre os temas abordados e as ferramentas do EOS utilizadas nas teses (Autores,

2021).

Tomando como referência que os números em vermelho indicam o número das teses (1, $2, \ldots, 16)$, que as siglas em verde se referem às ferramentas do EOS utilizadas e as siglas em azul aos temas abordados (ver legenda da Figura 4), de maneira geral, podemos observar que a maioria das teses utilizaram, ao mesmo tempo, a ferramenta Critérios de Adequação Didática $(\mathrm{Cl})$ e Conhecimentos e Competências Didático-Matemáticas (CCDM) conectadas com os temas Formação de Professores (FP). Por outro lado, por exemplo, apenas a T2 utiliza a ferramenta Análise de Trajetórias e Interações Didáticas, ferramenta implicada no terceiro nível de análise proposto pelo EOS.

Com relação a categoria articulação do EOS com outras abordagens teóricas, observa-se que oito teses realizam, em suas análises, tal articulação. Uma tese faz uma articulação do EOS com a Engenharia Didática, duas com 0 a teoria dos Registros das Representações Semióticas de Raymond Duval, três com outros modelos do conhecimento do professor (Lee Schulman e Deborah Ball), uma que utiliza o modelo da Teoria da Objetivação de Luis Radford e uma que utiliza, tanto a Engenharia Didática como a Teoria Antropológica do Didático de Yves Chevallard, conforme Figura 5. 


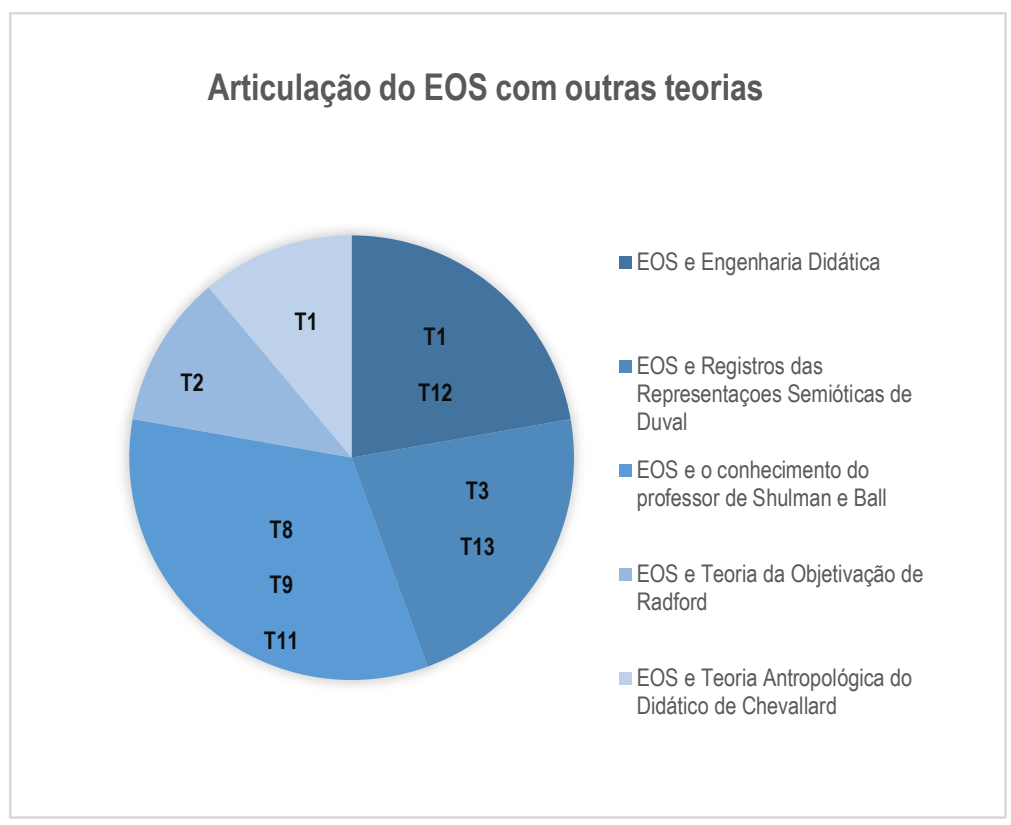

Figura 5: Articulação do EOS com outras abordagens teóricas (Autores, 2021).

As teses que relacionam o EOS com a Engenharia Didática utilizam as ferramentas Critérios de Adequação Didática (T12) e Configuração de Objetos e Processos (T1). As que relacionam o EOS com o Registro das Representações Semióticas de Raymond Duval, trabalham com a ferramentas: Identificação das práticas matemáticas (T3) e Configuração de objetos e processos (T3, T13). As que tratam da articulação do conhecimento do professor de Lee Schulman e Deborah Ball, usam as ferramentas Critérios de Adequação Didática (T8, T9, T11) e o modelo $\operatorname{CCDM}(T 9, T 11)$. A (T2) utiliza todas as cinco primeiras ferramentas do EOS e articula com a teoria da Objetivação de Luis Radford e, por fim, a (T1) utiliza ferramenta configuração de objetos e processos articulada com a Teoria Antropológica do Didático de Yves Chevallard. Observa-se que em relação aos trabalhos de articulação de teorias propostos pelo EOS, não encontrou-se nenhuma tese que realizasse um trabalho de articulação sobre a noção de significado de Louis Hjelmslev, Charles Sanders Peirce e Ludwing Wittgenstein, Friedrich Ludwig Gottlob Frege, Gérard Vergnaud e Horst Steinbring, nem com a Teoria Extendida das Conexões Matemáticas; nem com a Teoria APOS de Ed Dubinski, nem com a Teoria de Situações Didáticas de Guy Brosseau, nem com a Teoria de Campos Conceituais de Gérard Vergnaud; nem com a Teoria da Genesis Instrumental; tampouco com a Etnomatemática. 


\section{Considerações}

O objetivo deste trabalho foi analisar como se desenvolveram as pesquisas de doutorado no âmbito da abordagem Ontossemiótica no contexto brasileiro. Para isso, através de uma busca nos repositórios de teses e dissertações nacionais, encontrou-se um total de 16 teses publicadas de 2005 a 2019. A partir da metanálise realizada, conclui-se que a maioria das teses foram realizadas no estado de São Paulo e tiveram como lócus cursos e capacitação docente. Também se observa que o tema mais abordado foi a formação de professores e a ferramenta mais utilizada foram os Critérios de Adequação Didática $(\mathrm{Cl})$ seguida da Configuração de objetos e processos. Por fim, em oito teses encontra-se uma articulação do EOS com outras abordagens teóricas: Engenharia Didática, Registro das Representações Semióticas de Raymond Duval, conhecimento do professor de Lee Schulman e Deborah Ball, Teoria da Objetivação de Luis Radford e Teoria Antropológica do Didático de Yves Chevallard.

É importante destacar que este estudo permitiu estabelecer um panorama das teses que usaram a abordagem EOS realizadas no Brasil. Dos resultados encontrados, nota-se que, em termos nacionais, há poucas teses desenvolvidas e estas estão concentradas em apenas quatro estados brasileiros. Quanto aos níveis de ensino, há uma carência de estudos nos âmbitos da Pós-graduação e no Ensino Fundamental e total ausência de estudos no campo da Educação Infantil. Também, observa-se uma predominância do tema relacionado à formação de professores e do uso da ferramenta Critérios de Adequação Didática (Cl). A ausência ou pouco uso de algumas das ferramentas pode ser explicada pelas dificuldades de acesso à teoria do EOS por pesquisadores brasileiros, dado o idioma no qual ela se constitui e está majoritariamente difundida, o castelhano. Além disso, o pouco uso de algumas ferramentas pode ser devido à sua complexidade de aplicação nos dados coletados. Por fim, conclui-se que o estudo realizado aponta para um horizonte de possíveis futuras pesquisas que podem ser desenvolvidas no Brasil, em seus diferentes contextos, utilizando as diversas ferramentas do Enfoque Ontossemiótico.

\section{Agradecimentos}

Trabalho desenvolvido no marco do Projeto PGC2018-098603-B-I00 (MCIU/AEI/FEDER, UE) e com apoio da bolsa de estudo integral custeada integralmente pelo Município de Sapucaia do Sul, conforme processo seletivo realizado com base no Edital n 067/2020, da Unilasalle. 


\section{Referências}

BORJI, Vahid et al. Application of the complementarities of two theories, APOS and OSA, for the analysis of the university students' understanding on the graph of the function and its derivative. EURASIA Journal of Mathematics, Science and Technology Education, v. 14, n. 6, p. 23012315, 2018. DOI: 10.29333/ejmste/89514.

BREDA, Adriana. Características del análisis didáctico realizado por profesores para justificar la mejora en la enseñanza de las matemáticas. Bolema, v. 34, n. 60, 69-88, abr. 2020. DOI: 10.1590/1980-4415v34n66a04.

BREDA, Adriana; FONT, Vicenç; LIMA, Valderez Marina do Rosário. A noção de idoneidade didática e seu uso na formação de professores de matemática. Jornal Internacional de Estudos em Educação Matemática, v. 8, n. 2, p. 1-41, 2015. DOI: 10.17921/2176-5634.2015v8n2p\%25p.

BREDA, Adriana; FONT, Vicenç; PINO-FAN, Luís Roberto. Criterios valorativos y normativos en la Didáctica de las Matemáticas: el caso del constructo idoneidad didáctica. Bolema, v. 32, n. 60, p. 255-278, abr. 2018. DOI: 10.1590/1980-4415v32n60a13.

BREDA, Adriana et al. A investigação como princípio educativo na formação de professores de Ciências e Matemática. Caderno Pedagógico (Lajeado. Online), v. 13, n. 1, p. 107 - 123, 2016.

BREDA, Adriana et al. The Role of the Phase of Teaching and Observation in the Lesson Study Methodology. Bolema, v. 35, n. 69, p. 263-288, abr. 2021. DOI: 10.1590/1980-4415v35n69a13.

BREDA, Adriana; PINO-FAN, Luis Roberto; FONT, Vicenç. Meta Didactic-Mathematical Knowledge of Teachers: Criteria for The Reflection and Assessment on Teaching Practice. EURASIA Journal of Mathematics, Science and Technology Education, v. 13, n. 6, p. 18931918, 2017. DOI: 10.12973/eurasia.2017.01207a.

BREDA, Adriana et al. Teaching and learning of mathematics and criteria for its improvement from the perspective of future teachers: a view from the Ontosemiotic Approach. Mathematics Teaching Research Journal, v. 13, n. 1, p. 31-5, 2021.

BROUSSEAU, Guy. La tour de Babel. Etudes en Didactique des Mathématiques. Article occasionnel, n. 2, 1989. IREM de Bordeaux.

CARPES, Patrícia Pujol Goulart; BISOGNIN, Eleni. La formación continuada del profesorado desde la perspectiva del Conocimiento Didáctico Matemático. Revemop, v. 3, p. e202111, 23 jun. 2021. DOI: https://doi.org/10.33532/revemop.e202111

D'AMORE, Bruno ; GODINO, Juan Díaz. El enfoque ontosemiótico como un desarrollo de la teoría antropológica en didáctica de la matemática. Revista Latinoamericana de Investigación en Matemática Educativa, v. 10, n. 2, p. 191-218, jul. 2007. Disponível em https://www.redalyc.org/articulo.oa?id=33500202; acesso em 26 jun. 2021, às 17 h12.

DRIJVERS, Paul et al. One episode, two lenses. A reflective analysis of student learning with computer algebra from instrumental and onto-semiotic perspectives. Educational Studies in Mathematics, v. 82, n.1, p. 23-49, 2013. DOI: 10.1007/s10649-012-9416-8. 
FERNÁNDEZ, Tereza; GODINO, Juan Díaz; CAJARAVILLE, José Antonio. Razonamiento geométrico y visualización espacial desde el punto de vista ontosemiótico. Bolema, v. 26, n. 42a, p. 39-63, abr. 2012. DOI: 10.1590/S0103-636X2012000100004.

FONT, Vicenç; GODINO, Juan Díaz; GALLARDO, Jesús. The emergence of objects from mathematical practices. Educational Studies in Mathematics, v. 82, n.1, p. 97-124, 2013. DOI: 10.1007/s10649-012-9411-0.

FONT, Vicenç; PINO-FAN, Luis Roberto; BREDA, Adriana. Una evolución de la mirada sobre la complejidad de los objetos matemáticos. Revista Paradigma, v. 41, n. 1, p. 107-129, 2020. DOI: 10.37618/PARADIGMA.1011-2251. 2020.p107-129.id846.

FONT, Vicenç; PLANAS, Núria; GODINO, Juan Díaz. Modelo para el análisis didáctico en educación matemática. Infancia y aprendizaje, v. 33, n. 1, p. 89-105, 2010.

FONT, Vicenç et al. Mathematical objects through the lens of two different theoretical perspectives: APOS and OSA. Educational Studies in Mathematics, v. 91, n. 1, p. 107-122, 2015. DOI: 10.1007/s10649-015-9639-6.

GODINO, Juan Díaz. Diseño y análisis de tareas para el desarrollo del conocimiento didácticomatemático de profesores. En J. M. Contreras, G. R. Cañadas, M. M. Gea y P. Arteaga (Eds.), Actas de las Jornadas Virtuales en Didáctica de la Estadística, Probabilidad y Combinatoria (pp. 1-15). Granada, Departamento de Didáctica de la Matemática de la Universidad de Granada, 2013. Disponível em https://www.ugr.es/ jgodino/eos/Godino_2013_Dise\%F1o_tareas.pdf; acesso em 26 jun. 2021, às $19 \mathrm{~h} 47$.

GODINO, Juan Díaz. Presente y futuro de la investigación en didáctica de las matemáticas. Atas da 29 Reunião Anual da ANPED. Caxambu, Minas Gerais, 15-18 outubro, p. 1-24, 2006. Disponível em http://29reuniao.anped.org.br/trabalhos/trabalhos_encomendados/GT19/GT19\%20Ed\%20Mat\%20(Trabal ho\%20encomendado).pdf; acesso em 26 jun. 2021, às $19 \mathrm{~h} 27$.

GODINO, Juan Díaz. Síntesis del Enfoque Ontosemiótico del Conocimiento y la Instrucción Matemáticos: motivación, supuestos y herramientas teóricas. Universidad de Granada, 2014. Disponível em http://www.ugr.es/ jgodino/eos/sintesis_EOS_14abril14.pdf; acesso em 26 jun. 2021, às $18 \mathrm{~h} 40$.

GODINO, Juan Díaz et al. Una perspectiva ontosemiótica de los problemas y métodos de investigación en educación matemática. Revemop, v. 3, p. e202107, 21 jun. 2021. DOI: https://doi.org/10.33532/revemop.e202107

GODINO, Juan Díaz; BATANERO, Carmen. FONT, Vicenç. El Enfoque Ontosemiótico: Implicaciones sobre el carácter prescriptivo de la didáctica. Revista Chilena de Educación Matemática, v. 12, n. 2, p. 3-15, 2020.

GODINO, Juan Díaz; BATANERO, Carmen. FONT, Vicenç. The Onto-semiotic Approach: implications for the prescriptive character of didactics. For the Learning of Mathematics, v. 39, n. 1, p. 37-42, 2019.

GODINO, Juan Díaz; BATANERO, Carmen. Significado institucional y personal de los objetos matemáticos. Recherches en Didactique des Mathématiques, v. 14, n. 3, p. 325-355, 1994. 
GODINO, Juan Díaz; BELTRÁN-PELLICER, Pablo; BURGOS, María. Concordancias y complementariedades entre la Teoría de la Objetivación y el Enfoque Ontosemiótico. Revista Colombiana de Matemática Educativa, v. 5, n. 2, p. 51-66, 2020.

GODINO, Juan Díaz; BURGOS, María.; GEA, Magdalena. Analysing theories of meaning in mathematics education from the onto-semiotic approach. International Journal of Mathematical Education in Science and Technology, 2021. DOI: 10.1080/0020739X.2021.1896042.

GODINO, Juan Díaz; FONT, Vicenç; CONTRERAS, Ángel de La Fuente; WILHELMI, Miguel R. Una visión de la didáctica francesa desde el enfoque ontosemiótico de la cognición e instrucción matemática. Revista Latinoamericana de Investigación en Matemática Educativa, v.9, n. 1, p. 117-150, 2006.

GODINO, Juan Díaz et al. Aproximación a la dimensión normativa en Didáctica de la Matemática desde un enfoque ontosemiótico. Enseñanza de las Ciencias, v. 27, n. 1, p. 59-76, 2009.

GODINO, Juan Díaz et al. Enfoque ontosemiótico de los conocimientos y competencias del profesor de matemáticas. Bolema, v. 31, n. 57, p. 90-113, abr. 2017. DOI: 10.1590/1980$4415 \mathrm{v} 31 \mathrm{n} 57 \mathrm{a} 05$.

GODINO, Juan Díaz et al. Análisis de la actividad matemática mediante dos herramientas teóricas: Registros de representación semiótica y configuración ontosemiótica. Avances de Investigación en Educación Matemática, v. 10, p. 91-110, 2016.

HUMMES, Viviane Beatriz et al. Criterios de Idoneidad Didáctica en una clase basada en el Lesson Study. Revista Praxis \& Saber, Tunja, v. 11, n. 26, e10667, 2020. DOI: 10.19053/22160159.v11n26.2020.10667.

KAIBER, Carmen Teresa; LEMOS, Andrielly Viana; PINO-FAN, Luís Roberto. Enfoque Ontossemiótico do Conhecimento e da Instrução Matemática (EOS): um panorama das pesquisas na América Latina. Perspectivas da Educação Matemática, v. 10, n. 23, p. 531 -552, 2017.

LEGUIZAMÓN, José Francisco. Patrones de interacción comunicativa del profesor universitario de matemáticas: un estudio de caso. Praxis \& Saber, Tunja, v. 8, n. 16, p. 57-82, 2017. DOI: 10.19053/22160159.v8n16.2017.6200.

MALET, Omar; GIACOMONE, Belén; REPETTO, Ana María. La Idoneidad Didáctica como herramienta metodológica: desarrollo y contextos de uso. Revemop, v. 3, p. e202110, 22 jun. 2021. DOI: https://doi.org/10.33532/revemop.e202110

MOLINA, Oscar Jaime; FONT, Vicenç; PINO-FAN, Luis Roberto. Estructura y dinámica de argumentos analógicos, abductivos y deductivos: un curso de geometría del espacio como contexto de reflexión. Enseñanza de las Ciencias, v. 37, n. 1, p. 93-116, 2019.

MORAES, Roque.; GALIAZZI, Maria do Carmo. Análise textual discursiva. ljuí: Unijuí, 2011.

OLIVERAS, Maria Luisa; GODINO, Juan Diaz. Comparando el programa etnomatemático y el enfoque ontosemiótico: Un esbozo de análisis mutuo. Revista Latinoamericana de Etnomatemática, v. 8, n. 2, p. 432-449, jun/set. 2015. 
PINO-FAN, Luis Roberto; GODINO, Juan Díaz. Perspectiva ampliada del conocimiento didácticomatemático del profesor. Paradigma, v. 36, n. 1, p. 87-109, 2015. DOl: 10.37618/PARADIGMA.1011-2251. 2015.p87-109.id552.

PINO-FAN, Luis Roberto et al. The theory of registers of semiotic representation and the ontosemiotic approach to mathematical cognition and instruction: linking looks for the study of mathematical understanding. In Beswick, K., Muir, T., \& Wells, J. (Ed.), Proceedings of the 39th Conference of the International Group for the Psychology of Mathematics Education, Hobart, Australia: PME, v. 4, p. 33-40, 2015. Disponivel em http://docente.ulagos.cl/luispino/wpcontent/uploads/2015/04/RR_Guzman.pdf; acesso em 26 jun. 2021, às 21:00.

PINTO, Cândida Martins. Metanálise qualitativa como abordagem metodológica para pesquisas em Letras. Atos de Pesquisa em Educação (FURB), v. 8, p. 1033-1048, 2013.

RODRIGUES, Cassio. A abordagem processual nos estudos da tradução: Uma análise metaanálise qualitativa. Cadernos de Tradução (UFSC), Florianópolis, v. 10, n.2, p. 23-59, 2002

RODRÍGUEZ-NIETO, Camilo Andrés et al. Mathematical connections from a networking of theories between extended theory of mathematical connections and onto-semiotic approach. International Journal of Mathematical Education in Science and Technology, 2021a. DOI: 10.1080/0020739X.2021.1875071.

RODRÍGUEZ-NIETO, Camilo Andrés et al. Una visión desde la red de teorías TAC-EOS sobre el papel de las conexiones matemáticas en la comprensión de la derivada. Revemop, v. 3, p. e202115, 24 jul. 2021b. DOI: https://doi.org/10.33532/revemop.e202115

STEINER, Hans-Georg.Theory of mathematics education (TME): an introduction. For the Learning of Mathematics, v. 5, n. 2, p. 11-17, 1985.

WILHELMI, Miguel R; FONT, Vicenç; GODINO, Juan Díaz. Bases empiriques de modèles théoriques en didactique des mathématiques : réflexions sur la théorie de situations didactiques et le point de vue ontologique et sémiotique. Actas de Colloque International Didactiques : quelles références épistémologiques? Association francophone internationale de recherche scientifique en éducation (AFIRSE). Bordeaux, France, 25 al 27 de mayo de 2005. p. 1-10, 2005. Disponível em : http://www.ugr.es/ igodino/funciones-semioticas/bases_empiricas_5junio06.pdf. Acesso en 26 Jun. 2021 , às $21: 00$.

\subsection{Referências das teses do estudo}

ANDRADE, Luisa Silva. Currículos de matemática no ensino médio: um olhar sob a perspectiva do enfoque ontossemiótico do conhecimento e a instrução matemática. 2014. 257f. Tese (Doutorado em Ensino de Ciências e Matemática), Universidade Luterana do Brasil, Canoas.

APARICIO PEREDA, Ana Sofia. Avaliação das atitudes no curso de Estatística: contextos universitários latino-americanos. 2014. 189f. Tese (Doutorado em Educação) -Faculdade de Educação, Universidade de São Paulo, São Paulo.

ASSIS, Adriana Ferreira. A produção de significados matemáticos em um contexto de aulas exploratório-investigativas. 2012. 250 f. Dissertação (Mestrado em Educação) - Faculdade de Educação, Universidade Federal de Minas Gerais, Minas Gerais. 
BREDA, Adriana. Melhorias no ensino de matemática na concepção de professores que realizam o mestrado Profmat no Rio Grande do Sul: uma análise dos trabalhos de conclusão de curso. 2016. 335f. Tese (Doutorado em Educação em Ciências e Matemática) - Faculdade de Física, Pontifícia Universidade Católica do Rio Grande do Sul, Porto Alegre.

CARPES, Patricia Pujol Goulart. Conhecimentos didático-matemáticos do professor de matemática para o ensino de números racionais. 2019. 265f. Tese (Programa de PósGraduação em Ensino de Ciências e Matemática), Universidade Franciscana, Santa Maria.

CARVALHO, José Ivanildo Felisberto de. Um estudo sobre os conhecimentos didáticosmatemáticos de probabilidade com professores de matemática dos anos finais do ensino fundamental. 2017. 344f. Tese (Doutorado em Educação Matemática), Universidade Anhanguera de São Paulo, São Paulo.

CARVALHO, Marcos Pavani de. Um estudo da inserção de estudantes da licenciatura em matemática no contexto da escola pública: contribuições do PIBID. 2016. 208f. Tese (Doutorado em Educação Matemática), Universidade Anhanguera de São Paulo, São Paulo.

LEMOS, Andrielly Viana. Estudos de recuperação no ensino fundamental: uma investigação no âmbito da geometria sob a perspectiva do enfoque ontossemiótico do conhecimento e da instrução matemática. 2017. 354 f. Tese (Doutorado em Ensino de Ciências e Matemática), Universidade Luterana do Brasil, Canoas.

LOBO, Rogério dos Santos. A abordagem dada à taxa de variação no livro didático do ensino médio e a sua relação com o conceito da derivada no livro didático do ensino superior. 2017. 255 f. Tese (Doutorado em Educação Matemática) - Programa de Estudos Pós-Graduados em Educação Matemática, Pontifícia Universidade Católica de São Paulo, São Paulo.

MIGUEL, Maria Inez Rodrigues. Ensino e aprendizagem do modelo Poisson: uma experiência com modelagem. 2005. 270 f. Tese (Doutorado em Educação) - Pontifícia Universidade Católica de São Paulo, São Paulo.

RIBEIRO, Rogerio Marques. Modelagem Matemática e mobilização de conhecimentos didático-matemáticos na formação continuada de professores dos anos iniciais. 2016. 263 f. Tese (Doutorado em Educação), Universidade Federal de São Carlos, São Carlos.

SANTANA, Kátia Cristina Lima. Relação professor-materiais curriculares em Educação Matemática: uma análise a partir de elementos dos recursos do currículo e dos recursos dos professores. 2017. 163 f. Tese (Doutorado em Educação Matemática) - Programa de Estudos Pós-Graduados em Educação Matemática, Pontifícia Universidade Católica de São Paulo, São Paulo.

SILVA, José Fernandes da. Um estudo do programa de consolidação das licenciaturas no contexto da formação inicial de professores de matemática. 2017. 253f. Tese (Doutorado em Educação Matemática), Universidade Anhanguera de São Paulo, São Paulo.

SOARES, Maria Elaine dos Santos. Conhecimentos didático-matemáticos mobilizados por professores dos anos iniciais: uma análise sob a perspectiva do enfoque ontosemiótico. 2016. 230f. Tese (Doutorado em Ensino de Ciências e Matemática), Universidade Luterana do Brasil, Canoas. 
THIEL, Afrânio Austregésilo. Práticas matemáticas no plano cartesiano: um estudo da coordenação de registros de representação. 2013. 235 f. Tese (Doutorado em Educação Científica e Tecnológica) - Centro de Ciências da Educação, Universidade Federal de Santa Catarina, Florianópolis.

VIEIRA, Vanice da Silva Freitas. 0 Ensino de Matemática proposto na coleção de livros didáticos usados nos cursos técnicos de nível médio do IFECT Fluminense: contextos e aplicações. 2016. 199 f. Tese (Doutorado em Ensino de Ciências), Universidade Cruzeiro do Sul, São Paulo. 